\title{
Implementing a community-based parent training behavioral intervention for Autism Spectrum Disorder
}

\author{
Leila F. Bagaiolo ${ }^{1,6}$ \\ (iD) https://orcid.org/0000-0002-5566-8230 \\ Graccielle R. da Cunha ${ }^{1}$ \\ (iD) https://orcid.org/0000-0002-8143-7305 \\ Maria Luísa M. Nogueira ${ }^{2}$ \\ (iD https://orcid.org/0000-0001-9024-4671 \\ Mariana Braido 3,4 \\ (iD https://orcid.org/0000-0003-0865-7237
}

Daniela Bordini ${ }^{1}$

(iD) https://orcid.org/0000-0002-0291-7029

Tatiana N. D. Sasaki ${ }^{1,6}$

(iD) https://orcid.org/0000-0001-6794-619X

Claudia R. Pacífico ${ }^{5,6}$

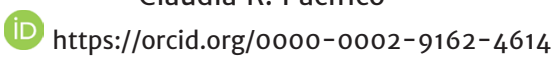

To cite this paper: Bagaiolo, L. F., Cunha, G. R., Nogueira, M. L. M., Braido, M., Bordini, D., Sasaki, T. N. D., \& Pacífico, C. R. (2019). Implementing a community-based parent training behavioral intervention for Autism Spectrum Disorder. Psicologia: Teoria e Prática, 21(3), 456-472. doi:10.5935/1980-6906/psicologia.v21n3p456-472

Submission: 09/04/2019

Acceptance: $12 / 06 / 2019$

(cc)BY

The content of Psicologia: Teoria e Prática is distributed under the terms of the Creative Commons Attribution License.

1 Federal University of São Paulo (Unifesp), São Paulo, SP, Brazil.

2 Federal University of Minas Gerais (UFMG), Belo Horizonte, MG, Brazil.

3 Pontifical Catholic University of Rio de Janeiro (PUC-Rio), Rio de Janeiro, RJ, Brazil.

4 Holy House of Mercy of Rio de Janeiro, Rio de Janeiro, RJ, Brazil.

5 University of São Paulo (USP), São Paulo, SP, Brazil.

6 Behavioral Intervention Group (Grupo de Intervenção Comportamental - GRADUAL), São Paulo, $\mathrm{SP}$, Brazil. 


\begin{abstract}
The autism spectrum disorder (ASD) affects developmental areas early in life and on families exert significant burden both emotionally and economically. This paper is a non-controlled, multicenter study to train caregivers of ASD individuals displaying disruptive behavior and deficit of communication, based on Applied Behavior Analysis. Results showed a reduction in the disruptive behavior measured by the Aberrant Behavior Checklist (ABC) and also the caregivers' depression and anxiety symptoms assessed by the Hamilton Scale. Group interventions may be an alternative for reaching a higher share of the population.

Keywords: autism spectrum disorders; parental training; applied behavior analysis; disruptive behavior management; functional communication training.

\section{CAPACITAÇÃO PARENTAL PARA MANEJO DE COMPORTAMENTOS DISRUPTIVOS PARA TEA EM INTERVENÇÃO COMPORTAMENTAL}

\begin{abstract}
Resumo
O transtorno do espectro do autismo (TEA) afeta precocemente áreas de desenvolvimento e resulta em uma sobrecarga significativa para as famílias, tanto emocional quanto economicamente. Este é um estudo não controlado, multicêntrico, com o objetivo de capacitar, com base na Análise Aplicada do Comportamento, cuidadores de indivíduos com TEA que apresentam comportamento disruptivo e deficit de comunicação. Os resultados mostraram redução nos comportamentos disruptivos, medidos pelo Aberrant Behavior Checklist ( $A B C$ ), e também nos sintomas de depressão e ansiedade dos cuidadores, avaliados pela Escala de Hamilton. As intervenções em grupo podem ser uma alternativa viável para atingir uma parcela maior da população. Palavras-chave: Transtorno do Espectro Autista; capacitação parental; análise do comportamento aplicada; gestão de comportamentos disruptivos; treino de comunicação funcional.
\end{abstract}

\title{
TEA: CAPACITACIÓN DE PADRES PARA MANEJO DE CONDUCTAS PROBLEMÁTICAS
}

\section{Resumen}

El trastorno del espectro autista (TEA) afecta temprano las áreas de desarrollo y resulta en una sobrecarga significativa para las familias, emocional y económicamente. Este es una investigación no controlada, multicéntrico, con el objetivo de capacitar, con base en el Análisis conductual aplicado, cuidadores de individuos con TEA - esos 
individuos con tea comúnmente presentan comportamientos disruptivos y déficit de comunicación. Los resultados indican reducción en los comportamientos disruptivos, medidos por el Aberrant Behavior Checklist (ABC) y reducción también en los síntomas de depresión y ansiedad de los cuidadores, evaluados por la Escala de Hamilton. Las intervenciones en grupo pueden ser una alternativa viable para alcanzar una cuota mayor de la población.

Palabras clave: trastorno del espectro autista; capacitación parental; análisis conductual aplicado; gestión de comportamientos disruptivos; entrenamiento de comunicación funcional.

\section{Introduction}

Prevalence estimates of global autism spectrum disorder (ASD) range from $0.72 \%$ to $0.76 \%$, and ASD is associated with major social impact (Baxter et al., 2015). A Brazilian populational prevalence survey estimates that the State of São Paulo has 40 thousand children and adolescents with ASD (Paula et al., 2011). Clinical deficits encompass two main domains: social communication and repetitive and stereotyped behaviors. Isolation and lack of interest in sharing with others, joint attention and symbolism deficits, diminished/lack of eye contact, inability to develop friendships and affective relationships and difficulty in understanding non-verbal communication are described as possible social communication impairments. Within the domain of repetitive and restricted behavioral patterns, inflexibility and rigid routines are commonly identified, as are motor or vocal stereotypes (body rocking, flapping, tip-toe walking, inadequate screaming, and continuous noise), restricted interests and topics, and hyper or hypo sensorial responsiveness (American Psychiatric Association, 2014).

Regarding ASD treatment, many studies have shown the effectiveness of ABA-based interventions. Some findings suggest positive effects on intellectual functioning, language development, self-help skills acquisition, and social functioning. Research has established promising effects of ABA intervention, even as a resource for public health and social policies concerning ASD and other neurodevelopmental disorders (Wong et al., 2014).

According to Maurice, Green, and Foxx (2001), the parameters for ABA intervention effectiveness include starting before the age of three and following specific procedures for each child with comprehensive activity programs so that all developmental domains are stimulated. These domains are progressively addressed 
according to individualized and intensive designs (20 to 40 hours a week) and must also be stimulated in other contexts and situations.

Family involvement in the therapeutic process is crucially relevant for the intervention in ASD individuals. Research evidence shows that parents whose children have been diagnosed with ASD are overloaded and face more challenges throughout their lifespan when compared to parents of children without neurodevelopmental disorders. Families need support when struggling with access to quality of information regarding treatment and diagnostic guidelines, including skills training, multidisciplinary coordination for legal and medical support; at the same time, the personal situation, such as social isolation, financial impact and family emotional condition, must be coordinated (Russa, Matthews, \& OwenDeschrer, 2015).

Another aim achieved through parent training is the creation of opportunities for ASD individuals to practice learned skills and enhance the generalization process. In such fashion, it is possible to consider that parent training has acquired a "co-therapist" education status. Parent training may be considered one of the most important cornerstones of behavioral intervention in ASD individuals. Strauss, Mancini, Fava, \& SPC Group (2013) recommend the development of protocols that provide parameters for parent training regarding program content and skills to be taught to ASD children. These procedures have to be implemented, applied and, mainly, have as a projected aim to reach the generalization of such skills and contents (Maurice et al., 2001; Strauss et al., 2013). Baer, Wolf, and Risley (1968) state that behavioral intervention must include the skills generalization process; that is, the skills must be maintained in various settings with various people. Therefore, parent training means planning generalization and effectively playing a role in behavior modification.

Wong et al. (2014), between 1900 and 2011, systematically reviewed published articles on ASD intervention, which have evidenced that parent training is scientifically effective for treatment. From the financial aspect, the cost of ABA intervention is elevated, given that the treatment is individualized, intensive, and lengthy. For this reason, according to Beaudoin, Sébire, and Couture (2014), investing in parent training may be a viable alternative in many cases.

In Brazil, since 2013, Grupo Gradual, in partnership with TEAMM (Social Cognition Outpatient Care - Dr. Marcos T. Mercadante - UNIFESP Psychiatry 
Department) and PROTEA (Autism Spectrum Disorder Program - Child and Adolescent Psychiatry Program of the Psychiatry Institute of the Clinical Hospital of São Paulo University Medical School), develops an ABA-based parent training model combining research and pro bono service, teaching different skills (Bagaiolo et al., 2018). Between 2013 and 2016, several structural and goal modifications have occurred until the program achieved its recent version, designed to teach how to manage disruptive behavior and functional communication, given that studies such as those of Vismara, Bogin, and Sullivan (2009) pointed out that teaching communication has been one of the main goals in parent training of children with ASD, as it is one of the major deficits related to such a condition (Bagaiolo et al., 2018).

Additionally, efficacy trials usually focus on a single specific main outcome with narrowly defined inclusion criteria and standardized procedures. Although this type of study is particularly important to establish internal validity, translating the findings to real-world situations may come across several obstacles (Hohmann \& Shear, 2002). Conversely, community-based programs tend to be characterized by more heterogeneous populations, with diversified outcome measures. Research trials conducted in a more naturalistic environment provide good opportunities for investigating the feasibility, acceptability, and generalizability of the intervention provided, allowing for the inclusion of individuals similar to those encountered in the clinical setting. Investigating the "noise" faced in real-world situations is particularly important in neurodevelopmental disorders like ASD that impact broadly distinct areas of life.

Parents were taught effective procedures validated by Behavior Analysis research to manage disruptive behaviors (Wong et al., 2014), focusing on differential reinforcement, providing positive reinforcing consequences for appropriate behavior, at the same time that disruptive behavior is extinguished (Vismara et al., 2009). They were also taught Functional Communication, the main purpose of which is to substitute disruptive behavior through differential reinforcement of more productive communication skills from a social point of view (using visual cues) (Bagaiolo et al., 2018). The aim of this study is to investigate the effectiveness of a community-based parent training behavioral intervention to reduce maladaptive behaviors in individuals with ASD. 


\section{Method}

This is a 10-weak multicenter open trial involving individuals with ASD. The trial was approved by the Ethics Committee (n. 742,331), and written informed consent was obtained from parents or legal guardians.

\subsection{Participants}

Participants were selected by convenience sampling. They were recruited from two tertiary outpatient services (Protea and Team) in the city of São Paulo. Additional participants were recruited through social media. The intervention has been provided twice a year since 2017. Participants had to have a diagnosis of ASD, impaired functional communication (speak less than ten words), the ability to communicate with gestures and identify figures and photos. Individuals receiving ABA-based intervention and/or using alternative communication systems, such as the Picture Exchange Communication System (Pecs), were excluded. Inclusion and exclusion criteria were assessed through an online questionnaire developed by the researchers.

\subsection{Assessment tools}

The following tools were used:

- Pre-group Questionnaire - as described under the Participants section.

- ABC Scale (Aberrant Behavior Checklist Scale): scale data sheet was answered by parents/caregivers. The ABC Scale is a five-factor scale comprising 58 items. The factors have been labeled as follows: I. irritability, agitation, crying (15 items); II. lethargy, social withdrawal (16 items); III. stereotypic behavior (7 items); IV. hyperactivity, noncompliance (16 items); V. inappropriate speech (4 items) (Losapio et al., 2011).

- Hamilton Depression Rating Scale (HDRS) - designed to assess patients previously diagnosed with depression, investigating symptoms severity level, and not their presence. The reduced version of the scale with 17 items was used. These items verify motor retardation, apathy, anxiety, suicidal thoughts, helplessness, and sleep pattern alteration (Freire et al., 2014). 


\subsection{Materials}

The following entry sheets were developed to collect data:

- Functional Hypothesis Questionnaire - eight questions regarding target behavior; prior (antecedent) and post (consequence) behavior situations.

- Disruptive Behavior Frequency Data Sheet - this sheet has seven main behaviors, among others, that participants may show, such as crying, screaming, throwing objects, self-injurious behavior, aggressive behavior, repetitive behavior and falling to the floor.

- Communication Frequency Sheet - showing different types of communicative behaviors to be marked at 15-minute intervals. A vertical slash will indicate how much and which communication took place in each observation interval.

- Pictures of items of interest to the child and of her/his routine schedule.

- Materials (EVA materials, satin ribbons, plastic).

\subsection{Procedures}

Outpatients in treatment who have met inclusion and exclusion criteria were invited to participate in the parent-training group. Another way to recruit participants was social media advertisement, informing email address, place and start date posted on Facebook and WhatsApp. Interested persons received a pre-group questionnaire by e-mail.

The training program had ten meeting sessions that provided visual resource lectures, practical examples, behavior shaping (successive approximation teaching), modeling (observation and imitation teaching), data entry and analysis, supervision with analysis of parents' homemade videos and role play.

On the first day of the course, participants were given the WICF (Written Informed Consent Form) and the Disruptive Behavior Frequency Sheet and received an explanation of how to enter data. Researchers also applied ABC and HDRS scales.

The $A B C$ Scale was used in three different moments of the course: in the first meeting and in the sixth and tenth days. All topics were explained to parents, and researchers read all questions to them. The HRDS Scale was applied in the first and last meetings. 
From the 2nd to the 4th meetings, it is provided basic theoretical basement of $A B A$, parents choose the behavior which is going to be minimized and registered, and a brief explanation of occupational therapy's view of the sensorial seeking behavior is given (stereotypies).

Three course meetings were used to produce work materials, namely, a routine board, a preference list, and a commitment board. Materials such as EVA, thermal laminating pouches, object pictures, and other general preference images, Velcro, and printing paper were provided by researchers in the meetings.

In the last 2-3 meetings, cumulative frequency charts of the two behaviors selected by participants were presented, and researchers talked about the use of the materials produced in the previous meetings.

\subsection{Statistical analysis}

Aiming to trace the epidemiologic profile of participants, descriptive statistical analysis was made according to the variables of interest. Categorical variables were summarized based on the response frequency for each category. Continuous variables were summarized based on measures of central tendency (mean and/or median) and measures of dispersion (standard deviation). Outcome and baseline variables (of participants who did the training, that is, those who delivered $80 \%$ of datasheets and had an attendance of $80 \%$, and those who did not do the training) were analyzed with paired sample $\mathrm{T}$-test and independent samples, respectively, with a significance level of 0.05 .

To absorb differences in amplitudes between independent variables that represent recorded behaviors, data was standardized. Such procedure consists of rescaling data to the same order of magnitude. Standardized data allows the adequacy for the relative analysis of each independent variable (Hair, Black, Babin, \& Anderson, 2009), meeting the need for visualization of the effect of the intervention program over time, in a relative manner and not in absolute terms. In this sense, standardized data was used to draw up accumulated frequency curves, therefore, allowing for comparison of the occurrence and variation of the different behaviors during the ten weeks of measurement.

The variability of patient responses over time is represented by curves created from the percentage difference in the number of cumulative occurrences recorded between periods (weeks). This perspective offers a second point of view for 
the perception of the rate of change in the patients' behaviors regarding stereotypes, alternatively to the view based on accumulated frequency. In other words, while cumulative frequency considers the absolute occurrence, variability indicates a gradual rate of change.

Interpretatively, large percentage variations suggest great variability in the patients' response, while a smaller percentage variation allude to greater stability. At the limit, perfect linearity would indicate total stability, in which the patient maintains the same pattern of occurrence of disruptive/stereotyped behaviors, with no progress or regression. In this sense, there is total predictability about the patient's behavior. This does not mean that the occurrence of disruptive/stereotyped behaviors ceases, but only remains unchanged.

Furthermore, in charts, cumulative frequency \& variability and general trend curves were inserted. These curves were drawn up based on the average of standardized data, as a means of generating a view of the general tendency in the sample studied. Both trend curves derive from a regression analysis of the data collected. The explanatory power of the trend curves is given by the coefficient of determination (R2), which varies from o to 1 , respectively indicating no (0\%) or total (100\%) data adherence to the generated model (Hair et al., 2009).

\section{Results}

Between March 2017 and November 2018, one hundred participants were included in the study. Descriptive characteristics are presented in Table 3.1.

Table 3.1. Baseline Demographic and Clinical Characteristics.

\begin{tabular}{|c|c|c|}
\hline \multirow{4}{*}{$\begin{array}{l}\text { Caregivers } \\
\mathrm{N}(\%)\end{array}$} & Mother & $114(95 \%)$ \\
\hline & Father & $5(4.2 \%)$ \\
\hline & Grandmother & 1 (0.8\%) \\
\hline & Total & $120(100 \%)$ \\
\hline \multirow{3}{*}{$\begin{array}{l}\text { Outpatient Service } \\
\mathrm{N}(\%)\end{array}$} & TEAMM & $71(59.2 \%)$ \\
\hline & PROTEA & $49(40.8 \%)$ \\
\hline & Total & $120(100 \%)$ \\
\hline
\end{tabular}

(continues) 
Table 3.1. Baseline Demographic and Clinical Characteristics.

\begin{tabular}{llc}
\hline $\begin{array}{l}\text { Adherence to treatment } \\
\mathrm{N}(\%)\end{array}$ & Yes & $43(35 \%)$ \\
\hline Child demographics & & \\
\hline Gender & Male & $111(84.2 \%)$ \\
\cline { 2 - 3 } $\mathrm{N}(\%)$ & Female & $19(15.8 \%)$ \\
\hline Age in years & Mean (SD) & $6.6(4.7)$ \\
\cline { 2 - 3 } & Maximum & 1 \\
\cline { 2 - 3 } & Minimum & 13 \\
\hline
\end{tabular}

Table 3.2 Shows that there was no statistic difference between the group of adherences versus the group of non-adherences when compared data from HDRS and $A B C$.

Table 3.2. Clinical characteristics at baseline and adherence to treatment.

\begin{tabular}{lccc}
\hline & $\begin{array}{c}\text { Adherent } \\
\text { Mean (SD) }\end{array}$ & $\begin{array}{c}\text { Non-adherent } \\
\text { Mean (SD) }\end{array}$ & $\boldsymbol{P}$ \\
\hline ABC & $62.8(27.0)$ & $58.9(24.8)$ & 0.440 \\
\hline HDRS & $11.9(4.4)$ & $13.7(6.8)$ & 0.128 \\
\hline
\end{tabular}

$A B C$ and HDRS scores were significantly lower at the end of the trial for participants who completed the intervention (Table 3.3).

Clinical characteristics of adherent participants indicate an ABC and HDRS scores significantly lower at the end of the trial for participants who completed the intervention (Table 3.3).

Table 3.3. Baseline and follow-up on outcome measure scores.

\begin{tabular}{lcccc}
\hline & N & $\begin{array}{c}\text { Baseline } \\
\text { Mean (SD) }\end{array}$ & $\begin{array}{c}\text { Follow-up } \\
\text { Mean (SD) }\end{array}$ & $P$ \\
\hline ABC & 42 & $62.76(27.0)$ & $49.8(24.17)$ & $<0.001$ \\
\hline HDRS & 32 & $11.87(4.4)$ & $8.9(4.6)$ & 0.05 \\
\hline
\end{tabular}

A polynomial regression model was the best fit for the cumulative record $(\mathrm{R} 2=0.99871)$. For the variability curve, the exponential model best fitted the data ( $22=0.99871)$ (Figure 3.1). 
Leila F. Bagaiolo, Graccielle R. da Cunha, Maria Luísa M. Nogueira, Mariana Braido, Daniela Bordini, Tatiana N. D. Sasaki, Claudia R. Pacífico

A polynomial regression model was the best fit for the cumulative record $(\mathrm{R} 2=0.99871)$. For the variability curve, the exponential model best fitted the data $(R 2=0.99871)$ (Figure 3.1).
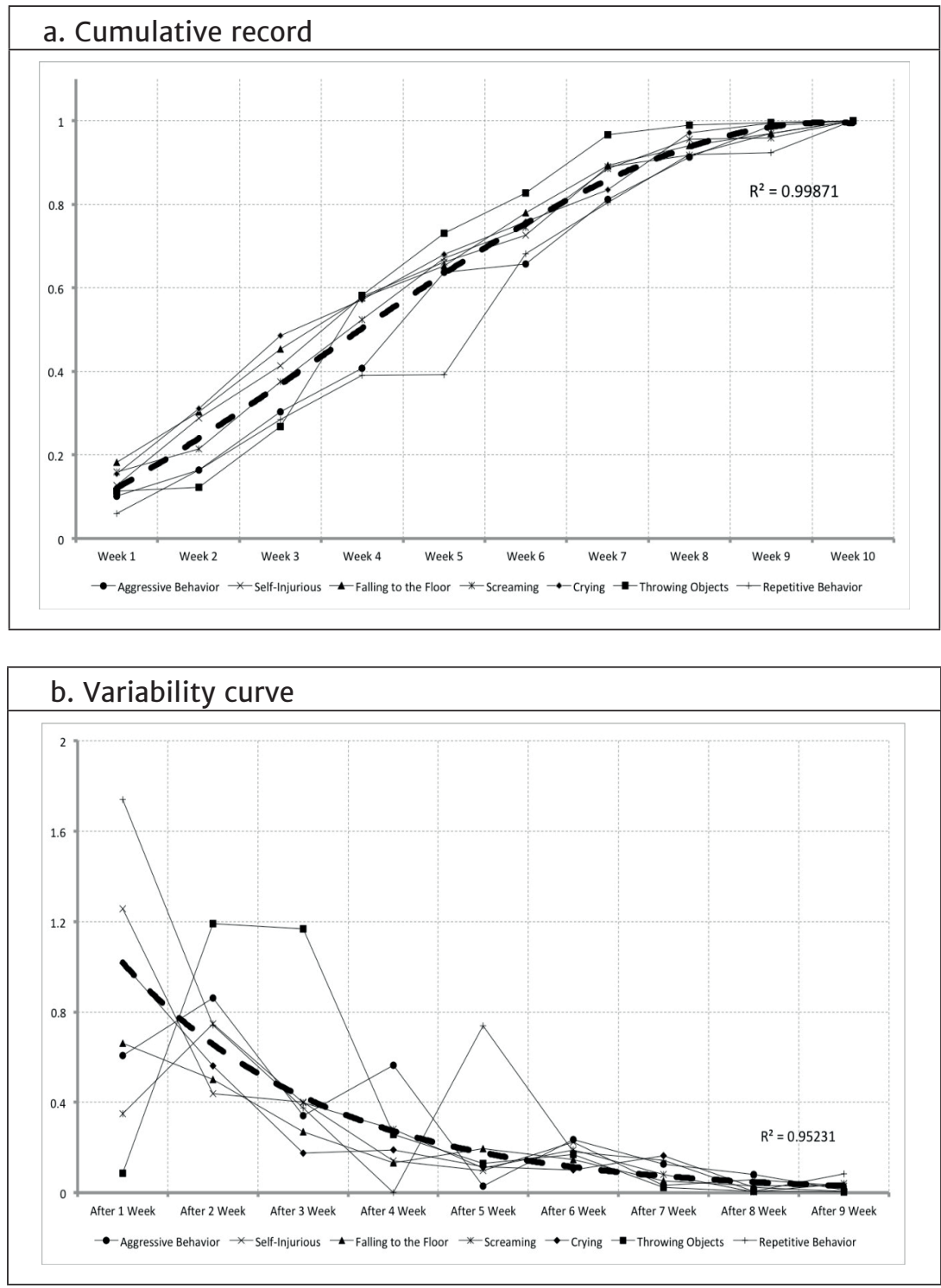

Figure 3.1. Cumulative record and variability curve for the frequency of disruptive behaviors. 
The cumulative frequency curve shows a trend of linear behavior up to week 7 , from which there is a marked decline in the number of occurrences. This nearly linear initial phase comprised about $87 \%$ of the total occurrences that were recorded, i.e., with each week alone accounting for about $12.4 \%$ of the total disruptive behaviors and stereotypes observed throughout the study. However, $7.5 \%, 2.7 \%$ and $2.8 \%$ of the total number of occurrences seen in the assessment period were observed respectively at weeks 8,9 and 10, indicating significant progress in the sample studied, in terms of reducing the frequency of disruptive behaviors and stereotypes.

\section{Discussion}

The present study assessed the impact of parent training focused on disruptive behavior management on caregivers of ASD individuals. In general, the main findings of the study showed improvement in behavioral problems in ASD individuals and in emotional and behavioral changes in caregivers. Evidence suggests the effectiveness of the package of procedures applied in the studied sample, resulting in a reduction of more than $70 \%$ in the last two weeks, compared to the frequencies observed in the initial stages of the research. In the seventh week, the process of guidance and transfer of the Functional Communication Training material package to the parents is completed, which could explain the significant increase noted in the subsequent weeks.

A diagnosis of ASD has a major impact on families. Data suggest that stress level generated by such diagnosis is greater than in other mental disorders, such as Attention Deficit and Hyperactivity Disorder (ADHD), Oppositional Defiant Disorder (ODD), depression, among others (Hayes \& Watson, 2013). Additionally, Bearss et al. (2015) and Da Paz and Wallander (2017) mention that the disruptive behaviors that cause impairments in everyday life and daily tasks may increase the likelihood of anxious and depressive symptoms in caregivers.

Behavioral management performed by family members is fundamental (Bearss et al., 2015), since, in some cases, ASD behaviors mix with the cardinal symptoms of autism. A careful functional assessment of these behaviors can identify functions related to avoidance of demands, social attention-seeking and sensorial deregulations and, through emergency communication training, it is often possible to prevent and redirect such difficult behaviors in the day-to-day of the 
individual and their family (Durand \& Merges, 2001; Carr \& Durand, 1985; Wacker et al., 2013).

Another important aspect to be highlighted as a product of this study was the difficulty of adherence of these caregivers in the ten meetings, since only 43 out of 120 participants started and finished the course. Possible impediments and aspects that might have deterred caregivers from attending the course up to the last encounter were listed, such as lack of family support; difficulty in performing and understanding the guidelines for acquiring new skills; financial or transportation difficulties; severity of patients' behavioral symptoms and severity of caregivers' depressive and anxious symptoms.

Although the dropout rates found in this study are high when compared to clinical trial rates (Cooper \& Conklin, 2015), they are similar to those found in other studies investigating treatment abandonment in "real world" situations (Zayfert, 2005). However, high dropout rates imply limitations in statistical evaluations and data generalization, being a limitation of this study. The possible explanations for the dropout rates found are common events in clinical practice.

Community-based programs require careful assessment of available resources and awareness of problems and needs in each setting. Particularly when resources are limited, developing affordable interventions require a proper understanding of the health system, including financing of care and services availability (McLeroy, Norton, Kegler, Burdine, \& Sumaya, 2003). Therefore, a major strength of this study was to include individuals most in need of treatment. The study group comprised of individuals that attended outpatient clinics, which had limited resources and no access to evidence-based interventions, and that is a situation very similar to the population who seek care in our public health system.

Limitations of this study include the absence of a control group and the lack of a direct assessment of individuals with ASD. Additionally, caregivers who took part in the intervention were the only source of information for outcome measures. Blinded outcome assessment and direct observation of participants' behavior represent an important step towards verifying the effectiveness of this intervention. Even though the present study indicated significant improvements in the depressive and anxious symptoms displayed by caregivers, further research is needed to identify whether causes of this decline are related to the reduction in maladaptive behaviors of the individuals with ASD. 
For future research, it would be important to trace possible profiles of the caregivers who adhered to the treatment, in order to optimize resources in public mental/health care centers and to understand possible causes of family abandonment (socioeconomic status, distance from family households to meeting centers and psychosocial support). The next steps may include controlled randomized trials, but we believe that even without them, the current data already represents a breakthrough in the available national literature.

The continuity of this work is extremely relevant in the Brazilian scenario since the shortage of trained professionals in behavior analysis and the high costs of intervention make access to this kind of treatment in the public service quite restricted. Taking this into consideration, the use of parent training groups increases the accessibility and the possibility of multiplication of behavior analysis knowledge to treat ASD.

This article is relevant in terms of Applied Behavior Analysis, as it proposed a package-using multicomponent and group intervention combining varied procedures and strategies. Smith (2013) discusses the broader effect of these package interventions in services and everyday life practice, without neglecting the individuality and the use of specific strategy, if needed.

\section{References}

American Psychiatric Association (2014) Manual diagnóstico e estatístico de transtornos mentais. (5. ed.) (Nascimento, M. I. trad.) Porto Alegre: Artmed.

Baer, D. M., Wolf, M. M., \& Risley, T. R. (1968). Some current dimensions of applied behavior analysis. Journal of Applied Behavior Analysis, 1(1), 91-97. doi:10.1901/ jaba.1968.1-91

Bagaiolo, L. F., \& Pacifico,C. R. (2018). Orientação e treino de pais: A necessidade da capacitação de pais de indivíduos com TEA e alguns parâmetros de evidência ciêntifica. In: C. P. Duarte, L. C. Silvia \& R. L. Velloso (Org.), Estratégia da Análise do comportamento Aplicada para pessoas com Transtornos do Espectro do Autismo (pp. 356378). São Paulo: Mennon.

Bagaiolo, L. F., Pacífico, C. R., Moya, A. C. C., Mizael, L. D. F., Jesus, F. S. D., Zavitoski, M., ... Asevedo, G. R. D. C. (2018). Capacitação parental para comunicação funcional e manejo de comportamentos disruptivos em indivíduos com Transtorno do Espectro 
Autista. Cadernos de Pós-Graduação em Distúrbios do Desenvolvimento, 18(2), 46-64. doi:10.5935/cadernosdisturbios.v18n2p46-64

Baxter, A. J., Brugha, T. S., Erskine, H. E., Scheurer, R. W., Vos, T., \& Scott, J. G. (2015). The epidemiology and global burden of autism spectrum disorders. Psychological medicine, 45(3), 601-613. doi:10.1017/So03329171400172X

Bearss, K., Johnson, C., Smith, T., Lecavalier, L., Swiezy, N., Aman, M., ... Sukhodolsky, D. G. (2015). Effect of parent training vs parent education on behavioral problems in children with autism spectrum disorder: A randomized clinical trial. Jama, 313(15), 1524-1533. doi:10.1001/jama.2015.3150

Beaudoin, A. J., Sébire, G., \& Couture, M. (2014). Parent training interventions for toddlers with autism spectrum disorder. Autism research and treatment, 2014. ID 839890. doi:10.1155/2014/839890

Carr, E. G., \& Durand, V. M. (1985). Reducing behavior problems through functional communication training. Journal of Applied Behavior Analysis, 18(2), 111-126.

Cooper, A. A., \& Conklin, L. R. (2015). Dropout from individual psychotherapy for major depression: A meta-analysis of randomized clinical trials. Clinical Psychology Review, 40, 57-65. doi:10.1016/j.cpr.2015.05.001

Da Paz, N. S., \& Wallander, J. L. (2017). Interventions that target improvements in mental health for parents of children with autism spectrum disorders: A narrative review. Clinical Psychology Review, 51, 1-14.

Durand, V. M., \& Merges, E. (2001). Functional communication training: A contemporary behavior analytic intervention for problem behaviors. Focus on Autism and Other Developmental Disabilities, 16(2), 110-119.

Freire, M. Á., Figueiredo, V. D., Gomide, A., Jansen, K., Silva, R. D., Magalhães, P. V. D. S., \& Kapczinski, F. P. (2014). Escala Hamilton: Estudo das características psicométricas em uma amostra do sul do Brasil. Jornal Brasileiro de Psiquiatria, 63(4), 281-289. doi:10.1590/0047-2085000000036

Hair, J. F., Black, W., Babin, B., \& Anderson, R. (2009). Multivariate data analysis. (P. Hall, Ed.) (7th edition). Essex: Pearson Education Limited.

Hayes, S. A., \& Watson, S. L. (2013). The impact of parenting stress: A meta-analysis of studies comparing the experience of parenting stress in parents of children with and without autism spectrum disorder. Journal of Autism and Developmental Disorders, 43(3), 629-642. 
Hohmann, A. A., \& Shear, M. K. (2002). Community-based intervention research: Coping with the "noise" of real life in study design. American Journal of Psychiatry, 159(2), 201-207. doi:10.1176/appi.ajp.159.2.201

Losapio, M. F., Silva, L. G., Pondé, M. P., Novaes, C. M., Santos, D. N. D., Argollo, N., ... Brasil, H. H. A. (2011). Adaptação transcultural parcial da escala Aberrant Behavior Checklist $(A B C)$, para avaliar eficácia de tratamento em pacientes com retardo mental. Cadernos de Saúde Pública, 27, 909-923. doi:10.1590/S0102-311X2011000500009

Maurice, C. E., Green, G. E., \& Foxx, R. M. (2011). Making a difference: Behavioral intervention for autism. Austin: Pro-Ed.

McLeroy, K. R., Norton, B. L., Kegler, M. C., Burdine, J. N., \& Sumaya, C. V. (2003). Community-based interventions. American Journal of Public Health, 93(4), 529-533. doi:10.2105/ajph.93.4.529

Paula, C. S., Ribeiro, S. H., Fombonne, E., \& Mercadante, M. T. (2011). Brief report: Prevalence of pervasive developmental disorder in Brazil: A pilot study. Journal of Autism and Developmental Disorders, 41(12), 1738-1742. doi:10.1007/ s10803-011-1200-6

Russa, M. B., Matthews, A. L., \& Owen-DeSchryver, J. S. (2015). Expanding supports to improve the lives of families of children with autism spectrum disorder. Journal of Positive Behavior Interventions, 17(2), 95-104. doi:10.1177/1098300714532134

Smith, T. (2013). What is evidence-based behavior analysis? The Behavior Analyst, 36(1), 7-33. doi:10.1007/bfo3392290

Strauss, K., Mancini, F., Fava, L., \& SPC Group (2013). Parent inclusion in early intensive behavior interventions for young children with ASD: A synthesis of meta-analyses from 2009 to 2011. Research in Developmental Disabilities, 34(9), 2967-2985. doi:10.1016/j.ridd.2013.06.007

Vismara, L., Bogin, J., \& Sullivan, L. (2009) Differential reinforcement of other behaviors: Steps for implementation. National Professional Development Center on Autism Spectrum Disorder. Sacramento, CA: University of California at Davis School of Medicine.

Wacker, D. P., Lee, J. F., Dalmau, Y. C. P., Kopelman, T. G., Lindgren, S. D., Kuhle, J., ... \& Waldron, D. B. (2013). Conducting functional communication training via telehealth to reduce the problem behavior of young children with autism. Journal of Developmental and Physical Disabilities, 25(1), 35-48. 
Wong, C., Odom, S. L., Hume, K. A., Cox, A. W., Fettig, A., Kucharczyk, S., ... Schultz, T. R. (2014). Evidence-based practices for children, youth, and young adults with Autism Spectrum Disorder. Journal of Autism and Developmental Disorders, 45(7), 1951-1966. doi:10.1007/s10803-014-2351-z

Zayfert, C., DeViva, J. C., Becker, C. B., Pike, J. L., Gillock, K. L., \& Hayes, S. A. (2005). Exposure utilization and completion of cognitive behavioral therapy for PTSD in a "real world" clinical practice. Journal of Traumatic Stress: Official Publication of The International Society for Traumatic Stress Studies, 18(6), 637-645.

\section{Authors notes}

Leila F. Bagaiolo, Department of Psychiatry, Federal University of São Paulo (Unifesp); Graccielle R. da Cunha, Department of Psychiatry, Federal University of São Paulo (Unifesp); Maria Luísa M. Nogueira, Department of Psychology, Federal University of Minas Gerais (UFMG); Mariana Braido, Extension Central Coordination Offices (CCE), Pontifical Catholic University of Rio de Janeiro (PUC-Rio); Daniela Bordini, Department of Psychiatry, Federal University of São Paulo (Unifesp); Tatiana N. D. Sasaki, Department of Psychiatry, Federal University of São Paulo (Unifesp); Cláudia R. Pacífico, Department of Psychiatry, University of São Paulo (USP).

Correspondence concerning this article should be addressed to Leila Felippe Bagaiolo, Rua Costa Carvalho, 231, São Paulo, SP, Brazil. CEP 05429-130.

E-mail: leila.bagaiolo@grupogradual.com.br 